\title{
Analysis and Modification of a Particle Filter Algorithm for Sensorless Control of BLDC Machine
}

\author{
Seyed Iman Hosseini Sabzevari, Yaser Chulaee, Salman Abdi
}

\begin{abstract}
This paper investigates the performance of a newly developed particle filter (PF) algorithm for sensorless control of the Brushless DC (BLDC) machines. A number of modifications have also been incorporated to the proposed $P F$ algorithm in order to improve its performance with respect to resampling process and robust operation when unpredicted disturbances are occurred. The disturbances investigated in this paper include the presence of unconventional Non-Gaussian noises, changes in machine's parameters, and occurrence of inter-turn short circuit fault. In addition, the paper proposes several measures in order to improve the estimation accuracy of the filter and enhance the filter robustness against system uncertainties. In order to evaluate the performance of the PF algorithm, the sensorless control system of a $1.5 \mathrm{~kW}$ BLDC machine is simulated in MATLAB/Simulink environment. Simulation results show that the introduced techniques considerably improve the performance of the $\mathrm{PF}$ algorithm as state estimator.
\end{abstract}

Index Terms -- Brushless DC (BLDC) Machine, Inter-turn Short Circuit Fault, Particle Filter, Resampling Process, Sensorless Drives.

\section{NOMENCLATURE}

$\begin{array}{ll}\text { i } & \text { Stator current } \\ V & \text { Terminal voltage } \\ \omega_{\mathrm{m}} & \text { Mechanical angular speed } \\ \theta_{\mathrm{m}} & \text { Mechanical position } \\ \mathrm{R}_{\mathrm{s}} & \text { Stator phase resistance } \\ \mathrm{L}_{\mathrm{s}} & \text { Synchronized stator phase inductance } \\ \mathrm{P} & \text { Number of poles } \\ \lambda & \text { Magnet flux linkage } \\ \mathrm{J} & \text { Moment of inertia } \\ \mathrm{B} & \text { Friction factor } \\ \mathrm{T}_{\mathrm{L}} & \text { Load torque } \\ \mathrm{f}\left(\theta_{\mathrm{m}}\right) & \text { Shape of stator phase back emf with the amplitude of } \pm 1 \\ \varepsilon(\mathrm{n}) & \text { Added noise } \\ \mathrm{N} & \text { Number of particles } \\ \mathrm{k} & \text { Step indicator } \\ \mathrm{Q}(\mathrm{m}) & \text { Cumulative sum of the first m normalized weight } \\ \mathrm{x} & \text { Posterior particle } \\ \hat{\mathrm{x}} & \text { Resampled particle } \\ \mathrm{p}(\mathrm{y} \mid \mathrm{x}) & \text { Condition probability of distribution function (pdf) } \\ \mathrm{K} & \text { Scaler tuning parameter }\end{array}$

Seyed Iman Hosseini Sabzevari is with Department of Engineering, Ferdowsi University of Mashhad, Mashhad, Iran (e-mail: imanhosseini@mail.um.ac.ir).

Yaser Chulaee is with the Department of Engineering, Ferdowsi University of Mashhad, Mashhad, Iran (e-mail: yaser.chulaee@mail.um.ac.ir).

Salman Abdi is with School of Engineering, University of East Anglia (UEA), Norwich, NR4 7TJ, UK (e-mail: s.abdi-jalebi@uea.ac.uk).

\section{INTRODUCTION}

TOWADAYS, brushless DC (BLDC) motors are widely used in various applications. Unlike the brushed motors, BLDC motors can continuously operate at their maximum torque, while generating low amount of audible noise [1]. In addition, BLDC motors have simple structure as well as lighter and more compact than traditional motors [2]. Because of the special distribution of the stator winding, only rotor position information of every 60 degrees is required for control of the machine's operation. However, for a more sophisticated control and to obtain full machine's performance, vector control method is used [3]. In this method, continues rotor position information is required. The rotor position can be sensed by employing optical encoders and resolvers, nevertheless, these are prone to failure and hence the overall machine's reliability is affected.

Sensorless control methods use voltage and current measurements for determining the rotational speed and position of the rotor, hence eliminating the use of mechanical sensors. Therefore, sensorless control methods have lower maintenance cost, optimised system size, and they are suitable to be used in harsh environment applications. However, one of the main drawbacks associated to sensorless control is its computationally expensive process. Other drawbacks include high sensitivity to environmental noise, system uncertainties, and low accuracy at low rotor speeds [4], [5].

A general strategy in sensorless control is the use of the stator winding's back emf [6]. The back emf technique can further divided into terminal voltage sensing [2], back emf integration [7], flux linkage [8], and freewheeling diode conduction [5], [9]. The major drawback to the back emf technique is that it is not capable of determining rotor position at low speeds since the back emf has small amplitude. In order to overcome this issue, auxiliary parameters are identified, which are independent of speed [1], [10]. Although, this method is independent of speed, high level of parameter sensitivity is still a major obstacle to its recognition.

To deal with those issues, advanced sensorless methods are proposed. These new closed-loop algorithms are based on nonlinear control methods, for instance, sliding-mode observer (SMO) [11], [12], and stochastic filters. Stochastic filters are powerful tools for the system control in the presence of system uncertainties and external noise signals. A wellknown stochastic filter being widely used in nonlinear control methods is the Kalman Filter (KF). In [13] a vector control for the BLDC motor is presented, where the back emf is estimated using a KF and the speed control is achieved, nevertheless, an everlasting error is existed for rotor position estimation. Nair 


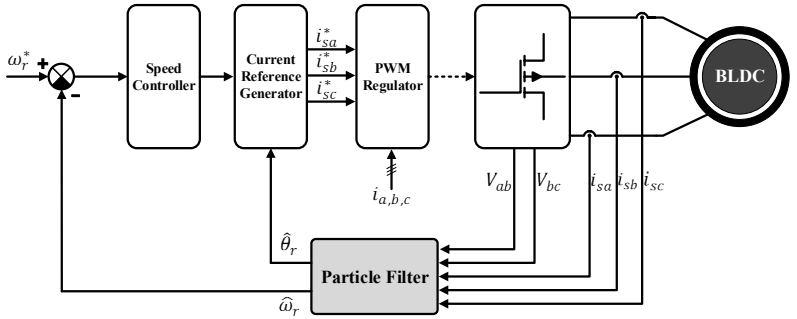

Fig. 1. The structure of sensorless control of a BLDC machine [17]

et. al. [14] also adopted a KF approach for sensorless direct torque control of a BLDC machine. However, a high level of error is observed in the estimated torque, as it is perceived that the conventional KF leads to accurate response only in linear systems. Therefore, other types of KF control, i.e. Extended Kalman Filter (EKF) [3, 15], Unscented Kalman Filter (UKF) [4], and Cubature Kalman Filter (CKF) [16], are introduced.

Particle Filter (PF) is an effective modern stochastic filter suitable for highly nonlinear systems, where the estimation error converges to zero in theory. The performance of the PF for position and speed estimation of the BLDC motor has been investigated by the authors and reported in [17]. This paper aims to analyse and modify the performance of the PF sensorless control proposed in [17].

In this paper the performance of a newly developed particle filter (PF) algorithm by the author for sensorless control of the BLDC machines is investigated. A number of modifications have also been incorporated to the proposed PF algorithm in order to improve its performance with respect to resampling process and robust operation when unpredicted disturbances are presented. The disturbances investigated in this paper include the presence of unconventional non-Gaussian noises, changes in machine's parameters, and occurrence of inter-turn short circuit fault. In addition, the paper proposes several measures in order to improve the estimation accuracy of the filter and enhance the filter robustness against system uncertainties. In order to evaluate the performance of the PF algorithm, the sensorless control system of a $1.5 \mathrm{~kW}$ BLDC machine is developed in Matlab/Simulink. The simulation results show that the introduced techniques considerably improve the performance of the PF algorithm as state estimator.

\section{Performance Analysis of the Particle Filter ALGORITHM}

A schematic of the sensorless drive system structure is shown in Fig. 1. As can be seen, the PF algorithm estimates the position and speed of the machine by using terminal current and voltage values. In such a drive system, only the machine's currents are measured, and the values of the line voltages are calculated using the state of operation of the converter and applied gate signals by the current reference
TABLE I

SPECIFICATIONS OF THE BLDC MACHINE CONSIDERED IN THIS STUDY

\begin{tabular}{lc}
\hline \hline Parameter & Value \\
\hline DC Link Voltage & $400 \mathrm{~V}$ \\
Power & $1.5 \mathrm{~kW}$ \\
Stator Phase Inductance $\left(\mathrm{L}_{\mathrm{s}}\right)$ & $8.5 \mathrm{mH}$ \\
Stator Phase Resistance $\left(\mathrm{R}_{\mathrm{s}}\right)$ & $2.88 \Omega$ \\
Number of Poles $(\mathrm{p})$ & 8 \\
Magnet Flux Linkage $(\boldsymbol{\lambda})$ & $0.175 \mathrm{~Wb}$ \\
Moment of Inertia $(\mathrm{J})$ & $0.0008 \mathrm{Kg} \cdot \mathrm{m}^{2}$ \\
Friction Factor $(B)$ & $0.001 \mathrm{Nm} / \mathrm{Rad} / \mathrm{Sec}$ \\
Speed & $150 \mathrm{Rad} / \mathrm{Sec}$ \\
\hline \hline
\end{tabular}

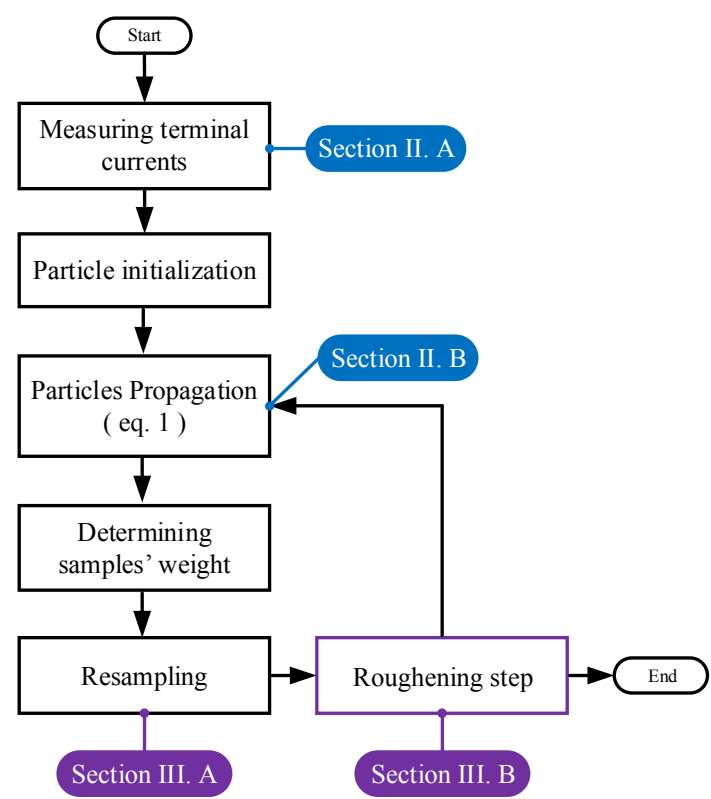

Fig. 2. The flowchart of the proposed PF algorithm. The colored marks illustrate the related section of the paper

generator. The estimated speed is then fed to the speed controller and the control unit produces gate signals accordingly using the estimated position and the generated reference currents. The mathematical matrix equation of the electrical and mechanical parameters of the BLDC machine are presented in (1). Fig. 2 illustrate the PF algorithm flowchart. A detailed analysis of the PF model development for the BLDC machine and its associated algorithm is presented in [17].

In this section, the performance of the proposed sensorless controller for BLDC machines is analysed with respect to the presence of Non-Gaussian noises and system parameters variations. The sensorless control system of the BLDC machine that utilises PF algorithm as state estimator is developed in Matlab/Simulink software. The specifications of
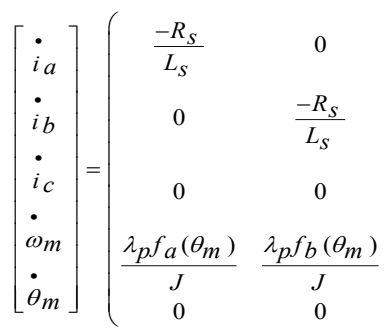

$$
\begin{gathered}
\frac{-\lambda_{p} f_{a}\left(\theta_{m}\right)}{L_{S}} \\
\frac{-\lambda_{p} f_{b}\left(\theta_{m}\right)}{L_{s}} \\
\frac{-\lambda_{p} f_{c}\left(\theta_{m}\right)}{L_{S}} \\
\frac{-B}{J} \\
1
\end{gathered}
$$

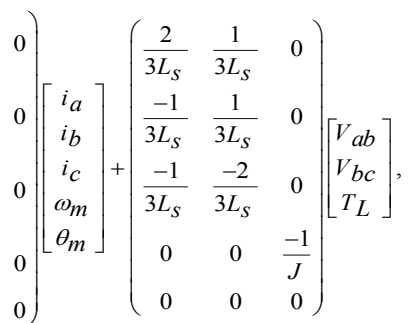

$y=\left(\begin{array}{lllll}1 & 0 & 0 & 0 & 0 \\ 0 & 1 & 0 & 0 & 0 \\ 0 & 0 & 1 & 0 & 0\end{array}\right)\left[\begin{array}{c}i_{a} \\ i_{b} \\ i_{c} \\ \omega_{m} \\ \theta_{m}\end{array}\right]$ 


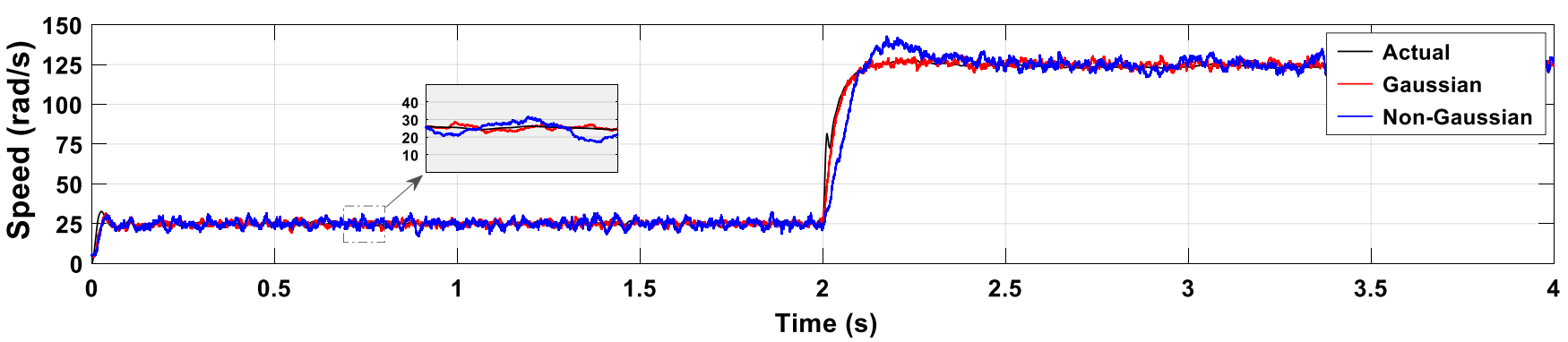

(a)

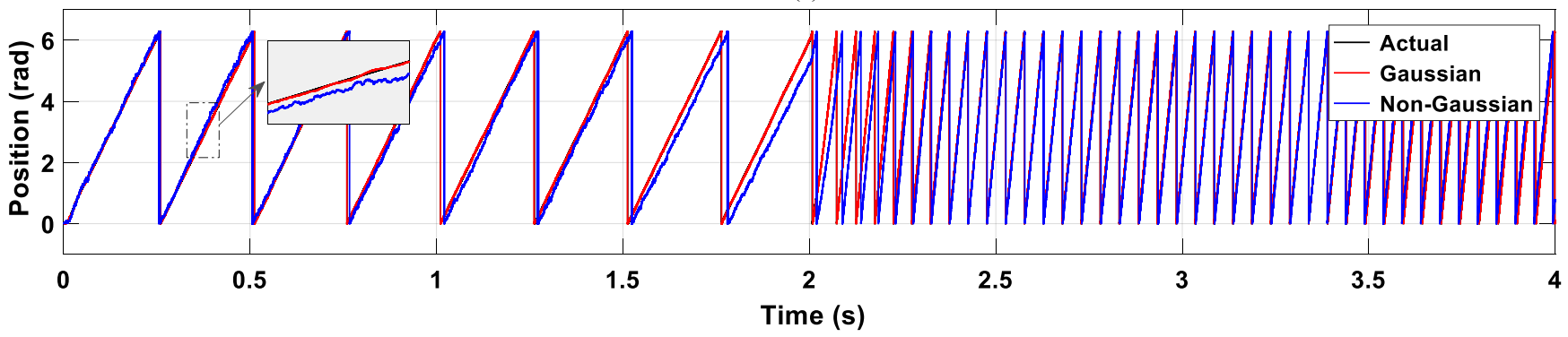

(b)

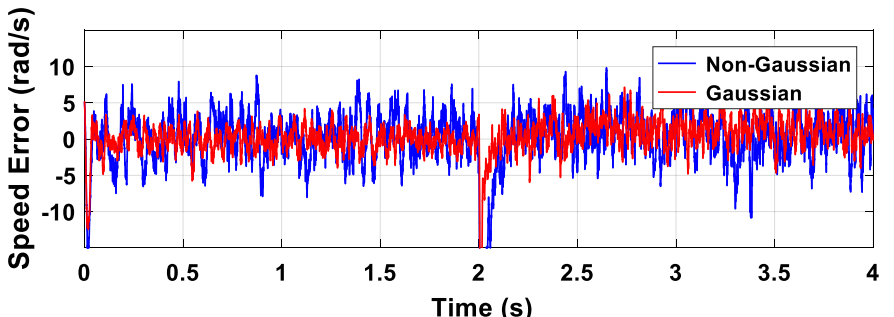

(c)

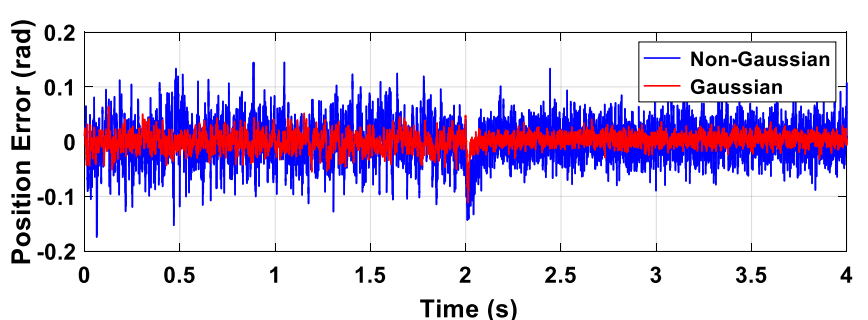

(d)

Fig. 3. The performance of PF algorithm in the presence of non-Gaussian noise: (a) speed estimation (b) position estimation (c) speed estimation error (d) position estimation error.

the BLDC machine considered in this study is presented in Table I.

A. Performance of PF Algorithm in the Presence of nonGaussian Noise

As mentioned earlier, different types of Kalman filters (KF) including EKF and UKF estimate the states of non-linear systems based on the assumption that the distribution of measurement noises and system uncertainties are Gaussian.

Although in most cases this assumption is valid for stochastic process, in some other, due to the variations in the behavior of the states and external circumstances, the assumption may become invalid [18], [19]. The variation in noise distribution can directly affect signal to noise ratio (SNR) of the PF input signal and hence if the filter has been tuned only for a specific range of SNR, the instability can occur in filter operation. This is particularly an issue for Kalman filter types e.g. EKF that utilise mean and variance of states throughout the estimation process. Nonetheless, the performance of the PF algorithm in the presence of nonGaussian noise is accurate and stable. This is because the PF performs a propagation of a set of particles in the system model to estimate the states, which is independent of the type of the noise presented in the system.

In order to evaluate the performance of $\mathrm{PF}$ algorithm in the presence of non-Gaussian noise, such a noise should be added to the machine current signals. Based on the Wiener approximation theorem every non-Gaussian noise can be stated as a finite sum of several Gaussian noises [18]-[20]. In other words, a non-Gaussian noise can be considered as a Gaussian noise with a random variable variance. Adding this noise to the measured current signals results in the SNR of the input signals varies during the PF operation. Therefore, a measured value can be considered as:

$$
u(n)=u^{\prime}(n)+\varepsilon(n)
$$

where $u(n)$ is the measurement values that are fed into the PF algorithm, $u^{\prime}(n)$ is the real measured signal, and $\varepsilon(\mathrm{n})$ is the added noise with the non-Gaussian distribution. Applying (2) to the PF model, the simulation results are shown in Fig. 3. Fig. 3(a) and 3(b) compares the performance of PF algorithm in the presence of Gaussian and non-Gaussian noises as well as the case where no noise to the current signal is considered. Figs. 3(c) and 3(d) compare the speed estimation error and position estimation error in the presence of Gaussian and nonGaussian noises, respectively. As can be seen, although the estimation error at the presence of non-Gaussian noise increased, PF algorithm is still sufficiently accurate and stable.

\section{B. Robustness to System Uncertanities}

One of the most important features for a state estimator is its resilience to the system parameter variations and uncertainties. In other words, a proper state estimator should be able to remain accurate and stable when system parameters deviate from their original values. In general, stochastic filters are more robust than other types of state estimators against 


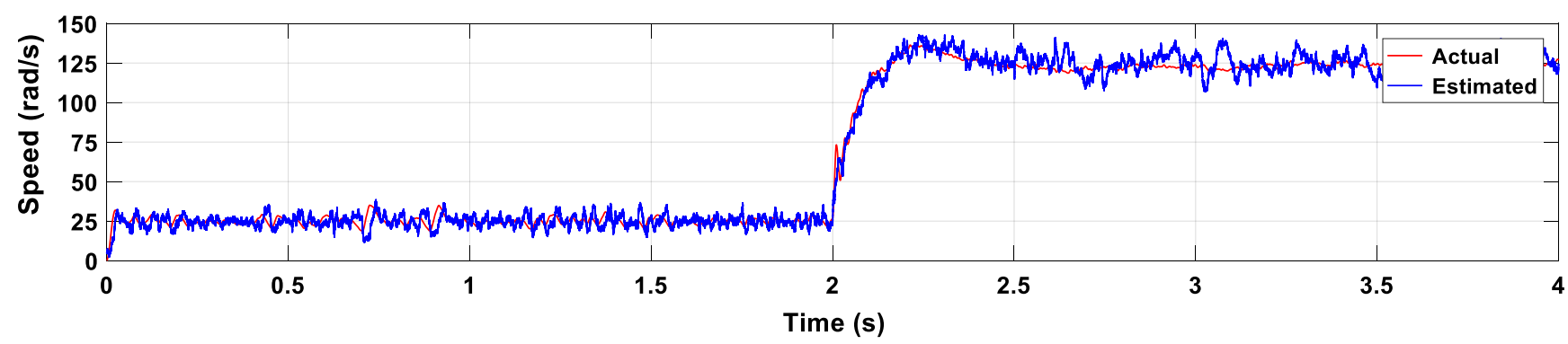

(a)

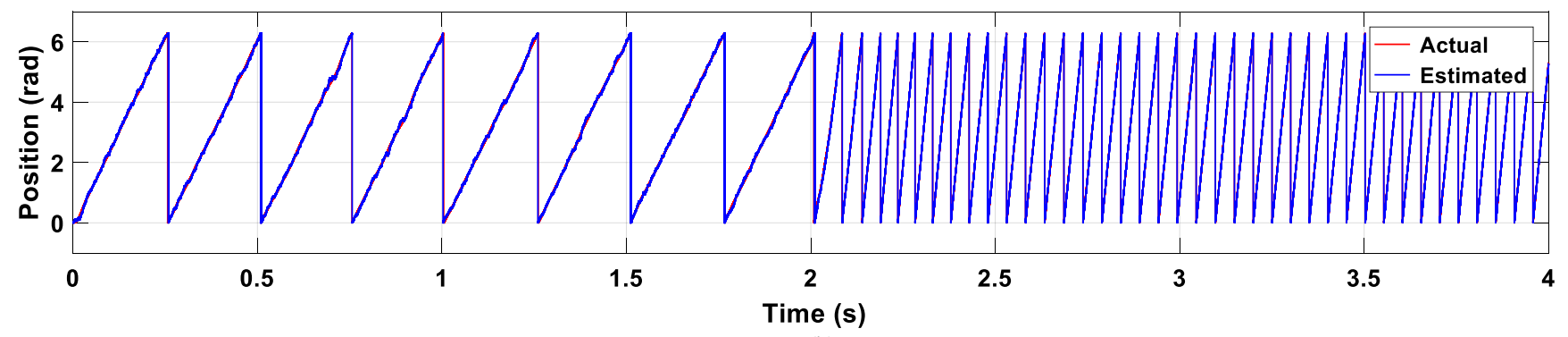

(b)

Fig. 4. Performance assessment of PF algorithm when $10 \%$ increase in resistance value is considered: (a) speed estimation (b) position estimation

variations of system parameters and uncertainties due to their stochastic nature.

For the case of a machine's drive system, the stator winding resistances experience the most frequent variation due to the temperature rise during the machine's operation. In order to evaluate such an effect in the performance of the PF algorithm, a $10 \%$ increase in the values of the stator winding resistances is considered, while other parameters remained unchanged and the results are shown in Fig. 4. It is assumed that the actual value of the stator winding resistance is increased from the beginning of the simulation while the PF algorithm use the old value of the stator winding resistance for calculation. As can be clearly seen, the mean error value is increased, but the accuracy of the estimation remains at acceptable level.

\section{MODIFying PARTICLE FILTER}

The capability of the PF algorithm in state estimation of the BLDC machine has been discussed in [17]. In this section, additional measures that can be taken to modify the proposed $\mathrm{PF}$ algorithm with respect to accuracy and reliability improvement and computational burden reduction is presented.

\section{A. Resampling Process Modification}

Resampling process is a critical step in the operation of the PF algorithm. In this step, particles that have lower value of likelihoods are replaced by those having higher values. In other words, through resampling process particles which are more probable to be the final estimation are kept, while those which are less likely to be the answer are removed. Therefore, appropriate resampling strategy plays a significant role in the accuracy and the quality of the final estimation of the PF algorithm. However, such a strategy suffers from long computational time in every iteration that filter algorithm runs. In [21]-[24] various types of resampling strategies have been presented. Multinomial, Stratified, and Systematic are of the most effective resampling methods that have been employed in PF algorithm for state estimation of relatively simple nonlinear systems with low number of states [21].

In the Multinomial method, at each iteration, $\mathrm{N}$ random numbers between $(0,1]$, i.e. $u_{t}(n)$, correspond to $\mathrm{N}$ particles that are generated. Next, each of the random numbers is compared with the cumulative sum of the normalised weights and the mth element, which satisfies (3) is determined. Then, the nth particle for the next iteration is selected with respect to (4). This resampling strategy fulfils the unbiasedness conditions [20].

TABLE II

COMPARISON OF PF ALGORITHMS PERFORMANCE WITH DIFFERENT RESAMPLING STRATEGIES

\begin{tabular}{lcccccc}
\hline $\begin{array}{l}\text { Resampling } \\
\text { Strategy }\end{array}$ & $\begin{array}{c}\text { Mean of } \\
\text { Spedimation } \\
\text { Error } \\
\text { Multinomial }\end{array}$ & $\begin{array}{c}\text { Maximum of } \\
\text { Speed Estimation } \\
\text { Error } \\
(\mathrm{rad} / \mathrm{s})\end{array}$ & $\begin{array}{c}\text { Mean of } \\
\text { Position } \\
\text { Estimation Error } \\
(\mathrm{rad})\end{array}$ & $\begin{array}{c}\text { Maximum of } \\
\text { Position } \\
\text { Estimation Error } \\
(\mathrm{rad})\end{array}$ & $\begin{array}{c}\text { Required Random } \\
\text { Number }\end{array}$ & $\begin{array}{c}\text { Average } \\
\text { Computational } \\
\text { Time } \\
(\mathrm{ms})\end{array}$ \\
\hline Stratified & 1.3210 & 23.0250 & 0.0092 & 0.1641 & $\mathrm{~N}$ & 0.2812 \\
\hline Systematic & 1.1789 & 12.2220 & 0.0105 & 0.0734 & 1 & 0.1875 \\
\hline
\end{tabular}




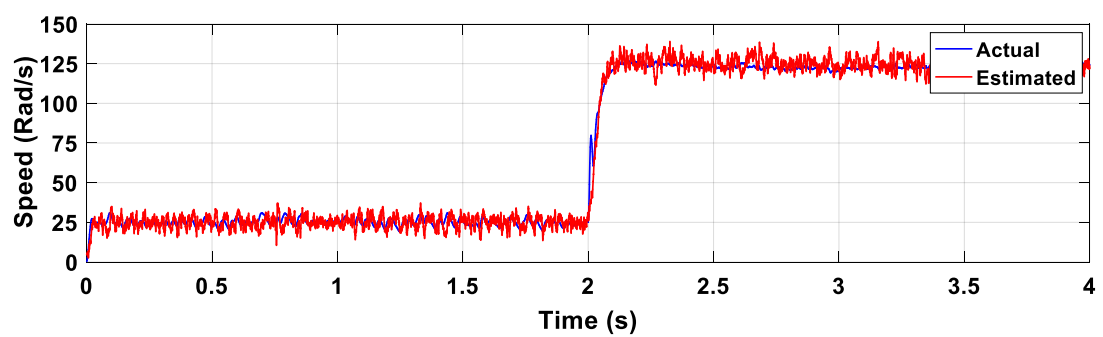

(a)

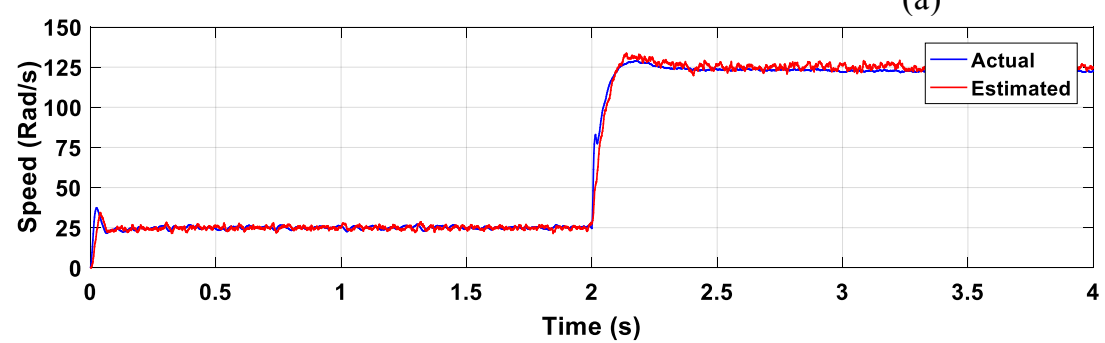

(b)

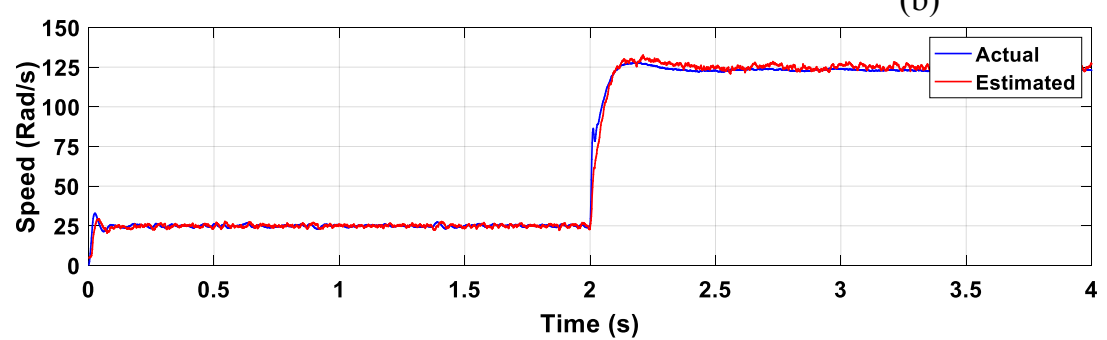

(c)
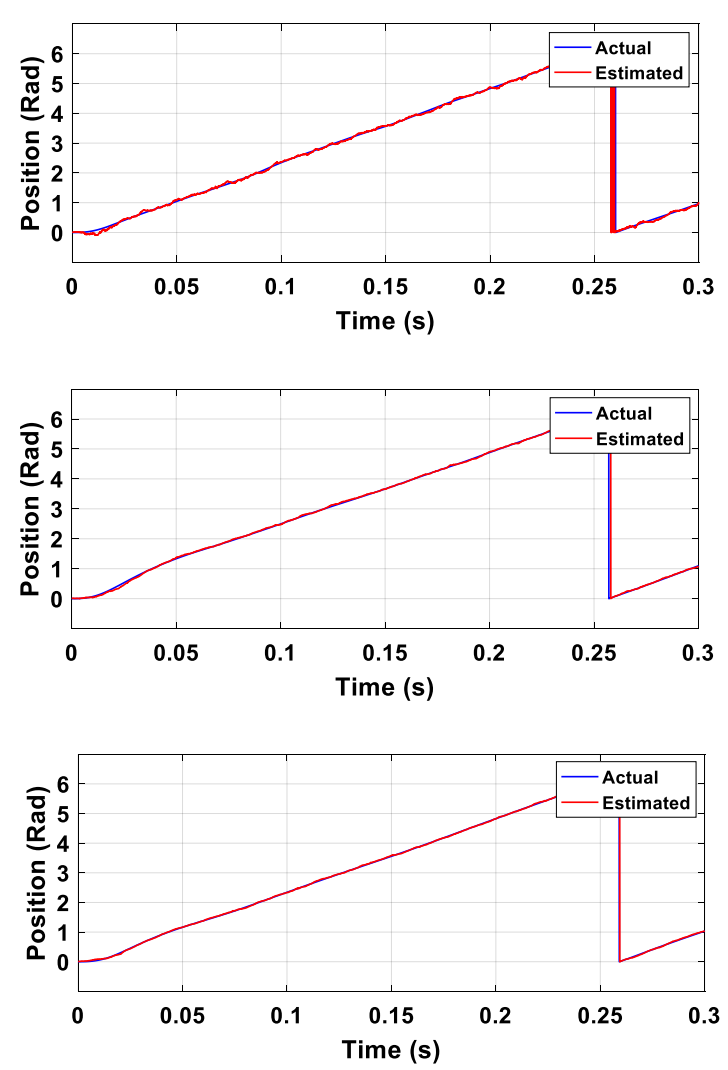

Fig. 5. Speed and position estimation obtained from sensorless control of the BLDC machine: (a) using a PF algorithm with Multinomial Resampling Strategy (b) using a PF algorithm with Stratified Resampling Strategy (c) using PF algorithm with Systematical Resampling Strategy.

$$
\begin{gathered}
Q_{t}(m-1) \leq u_{t}(n)<Q_{t}(m) \\
x_{t}(n)=\widehat{x}_{t}(m)
\end{gathered}
$$

The Stratified and Systematic resampling methods are both based on a shared principle of dividing the particles into sub-populations known as strata [20]. In Stratified strategy, a new random number is created for each strata by (5).

$$
u_{t}(n) \in\left(\frac{n-1}{N}, \frac{n}{N}\right], \quad n=1,2, \ldots N
$$

However, in the Systematic resampling strategy only one random number for the interval of $(0,1 / \mathrm{N}]$, i.e. $\mathrm{u}_{0}$, is generated and the required random number for other intervals are calculated by the following expression:

$$
u_{t}(n)=u_{0}+\frac{n-1}{N}, \quad n=2,3, \ldots N
$$

Then, the same approach as in Multinomial strategy will be carried out and the particles for the next iteration are selected with respect to the random numbers, following (3) and (4). In summary, the Systematic and Stratified strategies are less computationally demanding in comparison with Multinomial method.

As mentioned earlier, resampling strategy directly affects the performance of PF algorithm. In order to evaluate and compare the impacts of the mentioned resampling strategies on the performance of the proposed PF algorithm for a BLDC motor, the strategies are incorporated in three different $\mathrm{PF}$ models used for driving the BLDC machine, while the machine's parameters and other simulation variables are remained unchanged. Fig. 5 demonstrates the simulation results. As can be seen, the Multinomial method has the largest speed estimation error. In addition, there is no much difference between the performance of the Stratified and Systematic methods with respect to speed and position errors.

Table II also compares the estimation errors and computational time for the above strategies. The mean values of both the speed error and position error in Systematic method are lower than the Stratified approach, while no significant difference is noted between these strategies with respect to the computational time. It should be noted that the computational time is measured on the assumption that the number of the particles are equal to 100000 in order to make the processing time tangible.

\section{B. Enhancement of Filter Robustness to Parameter Variations.}

One of the most important issues in implementation of a stochastic filter is the reliability. In this study, the reliability refers to the ability of a filter to work under circumstances that the system deviates from its original status. In other words, how robust a stochastic filter operates when it faces variations in system parameters and environmental situations. Lack of robustness to such disturbances can lead the control algorithm to diverge causing significant negative impacts on the overall performance of sensorless drive system [25]. 


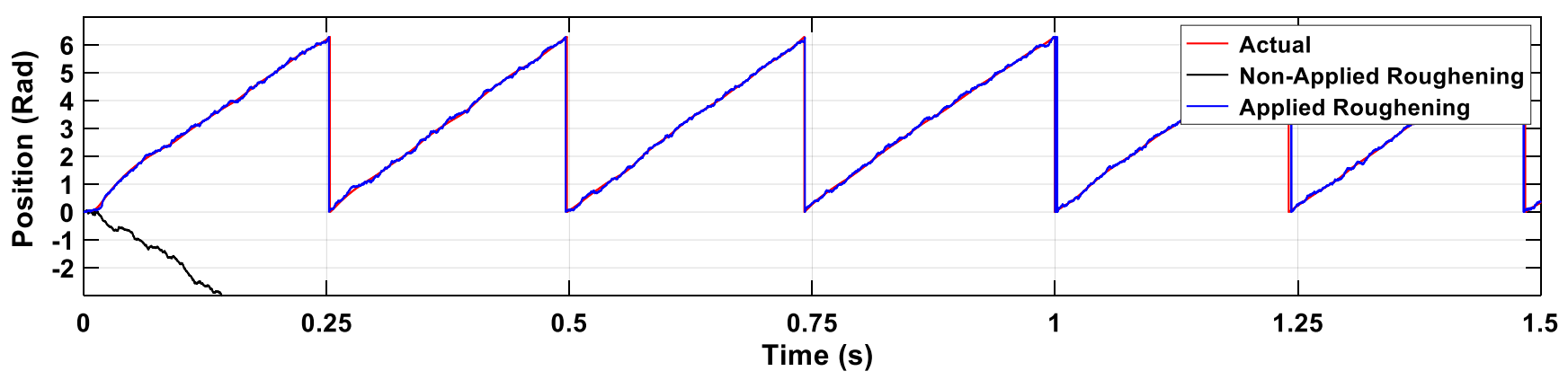

Fig. 6. The position state obtained from the simulation of PF algorithm in three different conditions. Condition 1: normal condition; Condition 2: when an inter-turn short circuit fault is applied with no change to the PF algorithm; Condition 3: when an inter-turn short circuit fault is applied, and roughening approach is used.

Due to modeling errors, unwarranted assumptions, and parameter variations, the actual system characteristics may be different with what is considered in system model. In the case of $\mathrm{PF}$ algorithm, the system model that is utilised to propagate particles and estimate parameters is not completely match with machine's parameters in practice. Therefore, the measurements are not consistent with the model being processed, and then the conditional probability distribution function (pdf) of $x_{k}$ and $y_{k}$, denoted by $P\left(y_{k} \mid x_{k}\right)$ does not match with the pdf $P\left(x_{k} \mid y_{k-1}\right)$. This essentially means that if the whole population of priori particles that are distributed according to $P\left(x_{k} \mid y_{k-1}\right)$ is resampled with respect to the computed pdf $P\left(y_{k} \mid x_{k}\right)$, only a few number of particles will be resampled to constitute posteriori particles. The main reason is that just a few numbers of the priori particles will be in a region of state space where the computed pdf $P\left(y_{k} \mid x_{k}\right)$ has a considerable value. Therefore, the resampling process will select only a few distinct priori particles to constitute posteriori particles. Finally, whole population of particles will converge to the same value. This phenomenon technically called sample impoverishment [25]. Many researches have been carried out to address this issue. For instance, a brute-force approach is proposed in [25] to increase the number of particles $\mathrm{N}$, but this can inevitably lead to unreasonable computational time, and often delays the inevitable sample impoverishment.

One of the most effective approaches to tackle this problem is roughening method [25], [26]. In this method, a random noise is added to each particle after the resampling process. This is similar to adding artificial noise to Kalman filter. In the roughening approach, posteriori particles that are essentially the output of the resampling step are modified as (7):

$$
x_{k, i}^{+}(m)=x_{k, i}^{+}(m)+\Delta x(m), \quad(m=1,2, \ldots n)
$$

where:

$$
x_{k, i}^{+}(m) \sim\left(0, K M(m) N^{-1 / n}\right)
$$

and $\Delta x(m)$ is a zero-mean random variable, usually with Gaussian distribution, $\mathrm{K}$ is a scalar tuning parameter, $\mathrm{N}$ is the number of particles, $\mathrm{n}$ is the dimension of the state space, and

$\mathrm{M}$ is a vector representing the values of the maximum differences between the particle elements before roughening. The mth element of the $\mathrm{M}$ vector is given by:

$$
M(m)=\max _{i, j}\left|x_{k, i}^{+}(m)-x_{k, j}^{+}(m)\right|, \quad(m=1,2, \ldots n)
$$

where $k$ is the time step, and $\mathrm{i}$ and $\mathrm{j}$ are particle numbers. The parameter $k$ is a tuning parameter that specifies the amount of artificial variations that is added to each particle.

In order to evaluate the practicality of using roughening approach in PF algorithm, the approach is implemented in the simulation model to assess the control system performance in the presence of a parameter changes in the machine. As mentioned in section II, changing stator winding resistance values due to temperature rise is one of the most frequent parameter variations in electrical machines. The stator winding faults such as inter-turn fault can also lead to variations in stator winding resistance values. The inter-turn fault mostly occurs due to insulation failure in windings leading to short circuit between two or more turns in a machine winding coil leading to reduction in stator resistance values. The resistance reduction can be considerable or negligible depending on the fault severity.

Fig. 6 shows the performance of the proposed PF algorithm while a severe inter-turn fault occurs in one phase of the stator winding of the BLDC machine. It is assumed that the resistance value of the phase is decreased by $25 \%$ due to the fault occurrence. As can be seen, in the presence of inter-turn fault and when the roughening method is incorporated to the PF algorithm, the control system can estimate the position similar to normal operation of the machine with acceptable accuracy. However, the same PF algorithm that does not utilise roughening approach is entirely diverged due to the mismatch between the machine's new and original resistance values. Therefore, by implementation of the roughening approach the control system robustness to the system parameter variation is increased.

\section{CONCLUSION}

This paper analysed the performance of a proposed PF algorithm as state estimator of a sensorless control of the BLDC machines. The performance of the PF algorithm when non-Gaussian noise is applied to the current signals is assessed. The simulation results have demonstrated that despite EKF algorithm, PF algorithm is capable of estimating 
the states of the system at the presence of non-Gaussian noises with acceptable accuracy. The effects of system parameter variations in the performance of the proposed filter has been analysed and the estimation accuracy has been investigated. Based on the results, the PF algorithm has shown to be capable of working appropriately machine's parameter variations. In addition, in order to improve the filter robustness when it is subjected to severe variations, roughening technique has been proposed. It has been shown that by incorporating the roughening approach, considerable improvement can be achieved in filter robustness by avoiding divergence in filter response when a large disturbance is presented. Moreover, three well-known resampling strategies have been incorporated to the PF algorithm of the BLDC machine and their performance with respect to computational time and estimation error have been compared concluding that the Stratified and Systematic resampling strategies are two effective and accurate methods and hence can be beneficial for sensorless control of the BLDC machines. In the future study, the experimental tests will conducted and the performance of the modified PF algorithm will be further investigated.

\section{REFERENCES}

[1] T.-H. Kim and M. Ehsani, "Sensorless control of the BLDC motors from near-zero to high speeds," IEEE transactions on power electronics, vol. 19, no. 6, pp. 1635-1645, 2004.

[2] P. Yedamale, "Brushless DC (BLDC) motor fundamentals," Microchip Technology Inc, vol. 20, pp. 3-15, 2003.

[3] B. Terzic and M. Jadric, "Design and implementation of the extended Kalman filter for the speed and rotor position estimation of brushless DC motor," IEEE Transactions on Industrial Electronics, vol. 48, no. 6, pp. 1065-1073, 2001

[4] H. Lv, G. Wei, Z. Ding, and X. Ding, "Sensorless control for the brushless DC motor: an unscented Kalman filter algorithm," Systems Science \& Control Engineering, vol. 3, no. 1, pp. 8-13, 2015.

[5] S. Ogasawara and H. Akagi, "An approach to position sensorless drive for brushless DC motors," IEEE Transactions on Industry Applications, vol. 27, no. 5, pp. 928-933, 1991.

[6] J. P. Johnson, M. Ehsani, and Y. Guzelgunler, "Review of sensorless methods for brushless DC," in Conference Record of the 1999 IEEE Industry Applications Conference. Thirty-Forth IAS Annual Meeting (Cat. No. 99CH36370), 1999, vol. 1, pp. 143-150.

[7] T. M. Jahns, R. C. Becerra, and M. Ehsani, "Integrated current regulation for a brushless ECM drive," IEEE Transactions on Power Electronics, vol. 6, no. 1, pp. 118-126, 1991.

[8] N. Ertugrul and P. Acarnley, "A new algorithm for sensorless operation of permanent magnet motors," IEEE Transactions on Industry Applications, vol. 30, no. 1, pp. 126-133, 1994.

[9] J. Shao, D. Nolan, and T. Hopkins, "A novel direct back EMF detection for sensorless brushless DC (BLDC) motor drives," in APEC. Seventeenth Annual IEEE Applied Power Electronics Conference and Exposition (Cat. No. 02CH37335), 2002, vol. 1, pp. 33-37.

[10] S. Chen, G. Liu, and L. Zhu, "Sensorless control strategy of a $315 \mathrm{~kW}$ high-speed BLDC motor based on a speed-independent flux linkage function," IEEE Transactions on Industrial Electronics, vol. 64, no. 11, pp. 8607-8617, 2017.

[11] A. Deenadayalan and G. S. Ilango, "Position sensorless sliding mode observer with sigmoid function for Brushless DC motor," in 2012 International Conference on Advances in Power Conversion and Energy Technologies (APCET), pp. 1-6, 2012

[12] R. I. Zhiligotov and V. Y. Frolov, "Development of the sensorless control system BLDC motor," in 2017 IEEE Conference of Russian Young Researchers in Electrical and Electronic Engineering (EIConRus), pp. 1109-1111, 2017.
[13] T. E. de Almeida, G. T. de Paula, A. G. de Castro, W. C. Pereira, and R. d. A. José, "Sensorless vector control for BLDC machine," in 2017 Brazilian Power Electronics Conference (COBEP), pp. 1-6, , 2017.

[14] D. S. Nair, G. Jagadanand, and S. George, "Sensorless direct torque controlled BLDC motor drive with Kalman filter algorithm," in IECON 2017-43rd Annual Conference of the IEEE Industrial Electronics Society, pp. 2160-2165, 2017.

[15] A. Ejlali and J. Soleimani, "Sensorless vector control of 3-phase BLDC motor using a novel Extended Kalman," in 2012 International Conference on Advances in Power Conversion and Energy Technologies (APCET), pp. 1-6, 2012.

[16] D. Potnuru, K. P. B. Chandra, I. Arasaratnam, D.-W. Gu, K. A. Mary, and S. B. Ch, "Derivative-free square-root cubature Kalman filter for non-linear brushless DC motors," IET Electric Power Applications, vol. 10, no. 5, pp. 419-429, 2016.

[17] Y. Chulaee, H. A. Zarchi, and S. I. H. Sabzevari, "State Estimation for Sensorless Control of BLDC Machine with Particle Filter Algorithm," in 2019 10th International Power Electronics, Drive Systems and Technologies Conference (PEDSTC), pp. 172-177, 2019.

[18] K. N. Plataniotis, D. Androutsos, and A. N. Venetsanopoulos, "Nonlinear filtering of non-Gaussian noise," Journal of Intelligent and Robotic Systems, vol. 19, no. 2, pp. 207-231, 1997.

[19] M. Raitoharju, R. Piché, and H. Nurminen, "A systematic approach for Kalman-type filtering with non-Gaussian noises," in 2016 19th International Conference on Information Fusion (FUSION), pp. 18531858, 2016.

[20] M. J. Mirza, "A modified kalman filter for non-gaussian measurement noise," in Communication Systems and Information Technology: Springer, pp. 401-409, 2011.

[21] J. D. Hol, T. B. Schon, and F. Gustafsson, "On resampling algorithms for particle filters," in 2006 IEEE nonlinear statistical signal processing workshop, pp. 79-82, 2006.

[22] T. Li, M. Bolic, and P. M. Djuric, "Resampling methods for particle filtering: classification, implementation, and strategies," IEEE Signal processing magazine, vol. 32, no. 3, pp. 70-86, 2015.

[23] M. Bolic, P. M. Djuric, and S. Hong, "Resampling algorithms and architectures for distributed particle filters," IEEE Transactions on Signal Processing, vol. 53, no. 7, pp. 2442-2450, 2005.

[24] G. Grisettiyz, C. Stachniss, and W. Burgard, "Improving grid-based slam with rao-blackwellized particle filters by adaptive proposals and selective resampling," in Proceedings of the 2005 IEEE international conference on robotics and automation, pp. 2432-2437, 2005.

[25] D. Simon, Optimal state estimation: Kalman, H infinity, and nonlinear approaches. John Wiley \& Sons, 2006.

[26] W. Zang, Z. Shi, S. Du, and K. Chen, "Novel roughening method for reentry vehicle tracking using particle filter," Journal of Electromagnetic Waves and Applications, vol. 21, no. 14, pp. 19691981,2007

\section{BIOGRAPHIES}

Seyed Iman Hosseini Sabzevari received the B.Sc. degree in Power Engineering and M.Sc. degree in Power Electronics from Ferdowsi University of Mashhad in 2013 and 2019, respectively. His main research interests are electric vehicles, energy sources, power electronics converters, electric drives and renewable energy systems.

Yaser Chulaee was born in 1994. He received the B.Sc. degree in electrical engineering from Shahrood University of Technology, Iran, in 2016, and the M.Sc. degree in electrical engineering from Ferdowsi University of Mashhad, Iran, in 2019. His research interests include electrical machines and drives and power electronic converters.

Salman Abdi received the B.Sc. degree from Ferdowsi University, Mashhad, Iran, in 2009, and the M.Sc. degree from the Sharif University of Technology, Tehran, Iran, in 2011, both in electrical engineering. He then completed the $\mathrm{Ph} . \mathrm{D}$. degree in electrical machines design and modeling from Cambridge University, Cambridge, U.K, in 2015. He is currently an Assistant Professor in Electrical Engineering at the University of East Anglia (UEA), Norwich, UK. His main research interests include electrical machines and drives for renewable power generation and automotive applications. 